\title{
Essential thrombocythemia - Incidence of thrombotic complications
}

${ }^{1}$ Faculty of Medicine, University "Ovidius" of Constanta

${ }^{2}$ Faculty of Dental Medicine, University "Ovidius" of Constanta

\begin{abstract}
Essential thrombocytemia is a classic negative chronic myeloproliferative disease $\mathrm{BCR}-\mathrm{ABL}$ characterised by global myeloid proliferation but mainly on the megacariocitary series. Most symptomatic patients show manifestations due to the vascular thromboses or haemorrhages. The objective of the paper is to evaluate the incidence of thrombotic complications.

The study was carried out in the Haematology Compartment of Constanta County Clinical Hospital on a lot of 60 cases with essential thrombocytemia.

The diagnosis criteria were OMS 2008 criteria.

On the studied lot, on the diagnosis, 45 patients (75\%) were symptomatic. Among the symptomatic ones 27 patients $(60 \%)$ showed thromboembolic manifestations in the moment of the diagnosis or after diagnosis.

The thrombotic manifestations present at the patients with essential thrombocytemia taken for the study were: cerebral micro thromboses -10 cases; peripheral micro thromboses - 3 cases; erythromelalgia - 6 cases; acrocyanosis - 2 cases; coronary thrombosis 1 case; portal vein thrombosis - 2 cases; pulmonary thromboembolism - 1 case; thrombosis of placenta vessels- 2 cases.

The thrombocytosis degree is not the only important risk factor for thrombosis. The age over 60 years, arterial hypertension, dyslipidemia, smoking, atherosclerosis, are associated risk factors (independent
\end{abstract}

\section{Ghinea Mihaela Maria}

Faculty of Medicine, University “Ovidius” of Constanţa

Aleea Universitatii, Nr. 1, Campus B

Constanţa, Romania

e-mail: ghinea_mihaela_maria@yahoo.com

phone: +40740312914 from thrombocytosis) for the frequency and severity of the thromboses. In this framework, on the one hand the increase of accessibility to the background therapy proven efficient (interferon, anagrelide) and on the other hand the mentioning in the cardiovascular pathology guides of primary and secondary thromboses as risk factors along with hypertension, diabetes, dyslipidemias, etc is required.

Keywords : essential thrombocytemia, thromboembolic manifestations, mutation JAK2V617F

\section{Introduction}

Essential thrombocytemia (TE) is a classic negative chronic myeloproliferative disease (BMP) BCR-ABL characterised by persistent thrombocytosis in the absence of another chronic myeloid disease or another cause of secondary thrombocytosis and the presence of the mutation JAK2V617F in $50-60 \%$ of the cases. TE is a clonal disease characterised by global myeloid proliferation but mainly on the megacariocitary series [1].

A variable percentage of the patients (between 20 and $70 \%$ according to studies) are asymptomatic. In these cases the diagnosis is put on the occasion of some hemograms carried out regularly or for other disorders. Most symptomatic patients show manifestations due to vascular thromboses or haemorrhages. After diagnosis, patients show thromboembolic manifestations in $25-80 \%$ of the cases [2]. 
Table I. Characteristics of the studied patients with TE

The objective of the paper is to evaluate the incidence of thrombotic complications in essential thrombocytemia.

\section{Material and method}

The study was carried out in the Haematology Compartment of Constanta County Clinical Hospital on a lot of 60 cases with $\mathrm{TE}$, that were registered between 1.01.2000 and 1.01.2016.

The diagnosis criteria were WHO 2008 criteria [3]:

1. Sustained thrombocytosis $>450 \times 109 / 1$

2. Presence of JAK2 or another clonal marker; in their absence, the exclusion of the causes of reactive thrombocytosis and/or iron deficiency.

3. The exclusion of the WHO criteria of diagnosis for other myeloid diseases: chronic myeloid leukaemia, vera polycitemia, myeloid metaplasis with myelofibrosis or myelodysplasic syndrome.

4. Ostheo medullary biopsy with hyperplasia of megakaryocytes (big, polilobed), absence / discrete proliferation of granulo and erytrocytary series; reticulin network below 2 (on a scale from 1-4)

\section{Results}

The studied lot comprised a number of 38 cases of feminine gender and 22 cases of masculine gender (Table I). The age of the patients ranged between 20 and 80 with an average of 55 years (Table I).

On the studied lot, at diagnosis, 45 patients (75\%) were symptomatic and only in 15 cases $(25 \%)$ thrombocytosis was an accidental discovery. Among the 27 patients $(60 \%)$ showed thromboembolic manifestations in the moment of diagnosis or after diagnosis (Table II).

Table II. Thrombotic manifestations present at patients with TE taken for study

\begin{tabular}{|l|c|}
\hline $\begin{array}{l}\text { Cerebral micro thromboses } \\
\text { (cephalgia, diziness) }\end{array}$ & 10 patients \\
\hline Peripheral micro thromboses & 3 patients \\
\hline $\begin{array}{l}\text { Erythromelalgia (paresthesias } \\
\text { and burns at the level of } \\
\text { extremities) }\end{array}$ & 6 patients \\
\hline $\begin{array}{l}\text { Acrocyanosis } \\
\text { Coronary thrombosis }\end{array}$ & 2 patients \\
\hline $\begin{array}{l}\text { Portal vein thrombosis } \\
\text { (TEP) }\end{array}$ & 2 patients \\
\hline Thrombosis of placenta vessels
\end{tabular}

Within the studied lot the number of thrombocytes was below 1 million in 40 cases and over 1 million in 20 cases (Table III). 
Table III. Changes of hemogram and bone marrow

\begin{tabular}{|c|c|}
\hline \multicolumn{2}{|c|}{ Number of thrombocytes $(550.000-2.100 .000 / \mathrm{mm} 3$} \\
\hline$<1$ million & 40 patients \\
\hline$\geq 1$ million & 20 patients \\
\hline \multicolumn{2}{|l|}{ Number of leukocytes } \\
\hline$<12000$ & 46 patients \\
\hline$\geq 12000$ & 14 patients \\
\hline Eosinophilia & 18 patients \\
\hline Basophilia & 16 patients \\
\hline \multicolumn{2}{|l|}{ Hemoglobin } \\
\hline$<11.5 \mathrm{~g} / \mathrm{dl}$ & 5 patients \\
\hline $11.5-15.5 \mathrm{~g} / \mathrm{dl}$ & 45 patients \\
\hline$>15.5 \mathrm{~g} / \mathrm{dl}$ & 10 patients \\
\hline \multicolumn{2}{|c|}{$\begin{array}{c}\text { Bone marrow (myelogram and osteomedullary } \\
\text { biopsy) }\end{array}$} \\
\hline $\begin{array}{l}\text { Hyperplasic (marked megakariocytary } \\
\text { hyperplasia ) }\end{array}$ & 55 patients \\
\hline Normoplasic & 5 patients \\
\hline
\end{tabular}

\section{Discussion}

Essential thrombocytemia is a disease that occurs at old ages, generally over 55 years, and rarely below 40 years. Less than $20 \%$ of the patients are below 40 years old. At patients below 40 years, TE is dominant in terms of incidence at the feminine gender.

On the studied lot, the ratio women/men was about 1.7 in favour of the feminine gender which agrees with the studies carried out by other authors. In this respect Fenaux and collaborators [4] quote a ratio of women/men of $2 / 1$.

The cases with cephalgia and dizziness were cardiologically (electro cardiogram, cardiac scan) and neurologically investigated (electroencephalogram, cranial CT) all without changes. The number of thrombocytres ranged in these cases between $600.000-800.000$ elements/mmc. In this clinical and biological framework we considered symptomatology as being owed to some platelet emboli or platelet aggregations at the level of small cerebral arteries. The symptomatology remitted after the introduction of anti aggregant treatment with aspirin and cytoreductor with hydroxycarbamide or thromboreductin.

Erythromelalgia was met on the studied lot in 6 cases. It started at distal extremity of the lower limbs by acroparesthesias, followed by burn type pains, erythema and heat in the distal part of the extremities. The phenomena were extremely painful and were triggered by sustained physical effort or heat. In one case the phenomena progressed towards cyanosis and necrosis of the distal phalange of fourth finger which required the amputation of the phalange.

Erythromelalgia represents the most frequent vessel occlusive manifestation being almost a patognomic sign for TE. Clinical manifestations are secondary to the disseminated thrombocytary aggregation and capillary toxic effects of metabolites of platelet arachidonic acid. Manifestations are calmed by inhibitors of cyclooxygenasis of aspirin type and by nonsteroidial anti-inflammatory drugs.

Thromboses of big vessels were met in three cases (one case of coronary thrombosis and 2 cases of portal vein thrombosis).

A 63 year old man showed arterial coronary thrombosis with acute non-fatal myocardial infarction. He also showed other factors of cardiovascular risk: obesity, dyslipidemia and sugar diabetes.

The degree of the thrombocytosis is not the only important risk factor for thrombosis. The age over 60 years, arterial hypertension, dyslipidemia, smoking, and atherosclerosis are associated risk factors (independent from thrombocytosis) for the frequency and severity of the thromboses [5].

Portal vein thrombosis was met in 2 cases. We show at length one of the cases of portal vein thrombosis.

Patient AC 45 years old at present, was diagnosed with TE in July 1996. After a long term favourable clinical evolution she is admitted in December 2001 with an algic syndrome of left hypocondrium of transfixing nature. In imagery terms portal vein thrombosis partially permeabilised with cavernomatous deformation in the hepatic hillum and secondary portal hypertension was confirmed. Furthermore, in ecographic terms splenomegaly was highlighted (long axle of the spleen of $14 \mathrm{~cm}$ ) with 
multiple splenic infarctions and in gastrofibroscopic terms esophageal varices of second degree were highlighted.

From the haematological exams at that time we acknowledged: the number of thrombocytes 800.000 elements $/ \mathrm{mmc}$, the number of leukocytes 12.000 elements $/ \mathrm{mmc}$ and haemoglobin $12 \mathrm{~g} / \mathrm{dl}$.

At this patient therapy was begun once with the occurrence of the thrombotic syndrome (antiaggregant, cytoreductor).

In 2003 the patients gets pregnant. In the moment of conception the disease was controlled with a normal number of thrombocytes. Taking into consideration the antecedents and in order to reduce the thrombogenic risk aspirin $100 \mathrm{mg} /$ day was introduced. In week 10 the patient loses pregnancy (spontaneous abortion). The cause of the abortion was represented by a placental insufficiency due to thrombosis of platelet vessels.

Thrombosis in antecedents represents risk factors for new thrombotic complications. At a patient that shows increased risk for similar events therapy is recommended even before pregnancy. Aspirin in low doses represents the minimum that is necessary $[6,7]$.

Essential thrombocytemia does not represent a counter-indication for keeping a pregnancy, but the two states of hypercoagulability show an additive risk, all the more so in the described case that had another thrombotic episode in antecedents.

Pregnant patients with TE have an increased risk of abortion in the first quarter, risk that cannot be predictable [6]. Even though there is a consensus on the fact that a good control of the disease before conception greatly reduces maternal risk, this did not occur in the shown case.

The tendency to thrombosis in TE occurs at a number of thrombocytes significantly lower than the level of thrombocytes to which the tendency to hemorrhage occurs.

Essential thrombocytemia is associated with thromboembolic complications most of the times when the number of the thrombocytes exceeds 600.00 / mmc. Thromboembolic complications including the severe ones are not unusual at relatively low values of thromboyctes.

On the studied lot the second case that showed at the beginning portal vein thrombosis had a number of thrombocytes $=560.000 / \mathrm{mmc}$. The 68 year old patient (2012) was admitted in emergency in a gastroenterology service for abdominal pains. CT exam a portal vein upper mesenteric thrombosis as highlighted. In the absence of the echographic exam and cyrotic liver $\mathrm{CT}$ an anticoagulant treatment was instituted to the patient to be subsequently reevaluated for other potential causes of thrombosis at the level of portal vein and upper mesenteric vein. In 2013 she is admitted in the hematology service where the diagnosis if essential thrombocytemia was established: the number of thrombocytes 552.000; osteomedulalry biopsy: histopathologic aspect compatible with a TE; mutation Jak2 V617F-positive. Abdominal CT: upper mesenteric thrombosis and portal vein thrombosis with portal cavernoma.

There are reported cases of thromboembolic complications that occurred at considerably smaller values of the thrombocytes.

In a study carried out in Mayo Rochester Clinic the issue of occurrence of thrombotic complications in TE was studied, at a relatively low number of thrombocytes. 56 patients with TE were taken in the study. Specific manifestations of TE were registered at 46 patients $(82 \%)$. Severe complications occurred at values of thrombocytes below $600.000 / \mathrm{mmc}$ at 10 patients $(22 \%)$, at below $500.000 / \mathrm{mmc}$ at 7 patients $(15 \%)$ and at lower values than $400.000 / \mathrm{mmc}$ at 2 of the patients $(4 \%)$.

Within the studied lot, the number of all the patients that showed thromboses was over 550.000/ mmc.

Thrombotic complications represent another major risk factor at patients with TE.

\section{Conclusions}

Thrombotic manifestations were present in $60 \%$ of the studied cases both at diagnosis and well as within the evolution of the disease.

Cerebral and peripheral micro vascular occlusions were the most frequent thrombotic 
complications (48\%).

Within the lot at the patients over 60 years in a percentage of $30 \%$ of the cases other risk factors were associated: arterial hypertension, dyslipidemia, sugar diabetes.

In the cardiovascular pathology guides it is necessary to mention primary and secondary thrombocytoses as risk factor along with arterial hypertension, sugar diabetes, dyslipidemias, and obesity.
7. Vantroyen, B. \& Vanstraelen, D. (2002). Management of Essential Thrombocythemia during Pregnancy with Aspirin, Interferon Alpha2a and No Treatment. Acta Haematologica. 107(3), 158-169. DOI:10.1159/000057634.

\section{References}

1. Petrov, L. (2009). Hematologie Clinică (pp.8290). Cluj-Napoca, Romania: Editura Casa Cărţii de Ştiinţă Cluj-Napoca.

2. Elliott, M.A. \& Tefferi,A. (2005). Thrombosis and haemorrhage in polycythaemia vera and essential thrombocythemia. Br. J. Haematol. 128(3), 27590. DOI: 10.1111/j.1365-2141.2004.05277.x.

3. Spivak, J. \& Silver, R.I. (2008). The Revised World Health Organization diagnostic criteria for polycythemia vera, essential thrombocytosis, and primary myelofibrosis: an alternative proposal. Blood. 112(2), 231-239. DOI: 10.1182/ blood-2007-12-128454.

4. Fenaux, P., Simon, M., Caulier, M. T., Lai, J. L., Goudemand, J. \& Bauters, F. (1990). Clinical course of essential thrombocythemia in 147 cases. Cancer. 66, 549-556. DOI: 10.1002/1097-0142(19900801)66:3<549::AIDCNCR2820660324>3.0.CO;2-6.

5. Hoffman, R. (2013). Hematologic malignancies. In R. Hoffman, E.J. Benz Jr., L.E. Silberstein, H. Heslop, J. Weitz \& J. Anastasi (Eds.), Hematology. Basic Principles and Practice $6^{\text {th }}$ edition (pp. 721-1375). Philadelphia, PA: Elsevier Saunders.

6. Greisshamer, M., Heimpel, H. \& Pearson, T.C. (1996). Essential thrombocythemia and pregnancy. Leukemia \& Lymphoma. 22(suppl 1), 57. DOI:10.3109/10428199609074361. 